\title{
COMO SE FABRICAM OS ANJOS? UMA ARQUEOLOGIA DO CORPO NOS MANUAIS ESCOLARES DE MORAL E DE HIGIENE NA FRANÇA, I880- 1974
}

\author{
DR. JACQUES GLEYSE \\ Doutor Ciências da Educação - Université de Paris X, Nanterre \\ Professeur des Universités à l'IUFM de Montpellier, Université de Montpellier 2 \\ (Montpellier - Hérault - França) \\ E-mail: jacques.gleyse@orange.fr

\section{DRA. CARMEN LÚCIA SOARES} \\ Doutora em Educação pela Universidade Estadual de Campinas (UNICAMP), \\ Professora Livre Docente pela Unicamp, Bolsista de produtividade em pesquisa do Conselho \\ Nacional de Desenvolvimento Científico e Tecnológico (CNPq) - História da Educação \\ (Campinas - São Paulo - Brasil) \\ E-mail: carmenls@unicamp.br
}

\begin{abstract}
RESUMO
A partir de um acervo constituído por 342 manuais escolares de moral e de higiene, o artigo analisa como se constitui um biopoder ou um micropoder no âmbito do discurso escolar. 0 corpo é ali fabricado, a carne é ali trabalhada como o fora por outras formas de livro (em grego Biblos). Vemos, claramente, aparecer através da arqueologia dos manuais escolares de moral e de higiene na França de fins do século XIX até os anos de 1970 que os preceitos judaico-cristãos, católicos, ou, mais largamente, monoteístas estão vivamente presentes nos manuais. Todavia, é importante sublinhar que esses manuais são parte constitutiva da escola republicana, que, na França, é descrita segundo as leis de 1905, como instituição separada da Igreja e, após as leis elaboradas por Jules Ferry (I 880- I 882), como instituição laica.
\end{abstract}

PALAVRAS-CHAVE: Corpo; moral; higiene; biopoder. 
"A cólera não faz nada além de tornar nossos esforços inúteis, ela é uma péssima conseIheira: se nós a escutamos, ficamos quase sempre a nos arrepender, a nos penitenciar" (PIERRE; MINET; MARTIN, 1920, p. 25 passim).

"O guloso, diz um velho provérbio, cava a sua sepultura com os dentes" (PIERRE; MINET; MARTIN, 1920, p. 25 passim).'

Os pequenos trechos em epígrafe foram extraídos dos manuais de higiene e de moral, fontes privilegiadas da pesquisa realizada e que apresentamos aqui, bastante resumida, na forma deste artigo. Ao escolher esses extratos, desejamos também evocar nossas lembranças, pois, certamente e sem muito esforço, encontraremos esse tipo de máximas guardadas em algum recanto de nossa memória. A questão que se coloca, então, é a de saber até que ponto esses elementos, facilmente lembrados, constituem o mais profundo de nossa corporalidade, constituem mesmo o nosso corpo.

A civilização dos costumes, ou seja, o controle das manifestações animais e da violência interindividual direta, se inicia, segundo Jérôme Thomas (2003), nas comunidades monásticas, a partir do século XIII, e de resto toca, segundo Elias, as cortes reais, no século XVI (ELIAS, 1973, 1975; THOMAS, 2003). Esse processo objetiva colocar à distância as pulsões, buscando civilizar nobres provincianos e outros aristocratas, a alta burguesia e mais tarde a média burguesia para, por intermédio da escola que se generaliza na Europa desde fins do século XIX, tocar todas as camadas sociais. Ele contribuirá de modo significativo, para colocar em evidência o lugar da "etiqueta" e de um estilo de vida largamente difundido a partir do século XIX nos manuais de savoir-vivre, sobretudo na França (PICARD, 1984). Talvez esse processo também venha a evidenciar as neuroses da civilização, à medida que ele organiza, sob múltiplas formas, micro poderes (FOUCAULT, 1975, 2004), buscando "proteger" os seres humanos de sua própria animalidade.

$\mathrm{Na}$ França, a partir do fim do século XIX e especialmente com o surgimento da escola republicana, gratuita, laica e obrigatória iniciada por Jules Ferry ( 880 - | 882), os manuais escolares de moral, mas também de higiene - considerados na França um discurso homogêneo -, certamente participaram de maneira importante nesse

I. "Le gourmand, dit un vieux proverbe, creuse sa fosse avec ses dents"; "On risque de payer bien cher la manie de toucher à tout"; "La colère ne peut que rendre nos efforts inutiles, c'est une mauvaise conseillère: si on l'écoute, on a presque toujours à s'en repentir" (PIERRE; MINET; MARTIN, 1920, p. 25 passim). 
processo de civilização dos costumes. Mesmo antes da iniciativa de Jules Ferry, a generalização das escolas religiosas de Jean-Baptiste de Lasalle, de certo modo, já prepararam essa escola generalizada e destinada, num primeiro momento, à idade de 6 a 12 anos. Após 1880, muitas gerações entraram em contato, de maneira constante e contínua, durante algumas horas semanais, com representações iconográficas, preceitos, parábolas, historietas, recitações, anedotas e outros conteúdos presentes nos manuais escolares de moral e de higiene. ${ }^{2}$

De um modo mais amplo, seria então possível imaginar que todas as representações gráficas ou iconográficas presentes nesses pequenos livros de uso escolar obrigatório, e considerando que eles afetam gerações sucessivas, produzem um efeito importante na configuração das concepções de mundo e nas representações sociais. Poderíamos então afirmar que, em primeiro lugar, essas representações gráficas vão alcançar toda uma geração com idade entre 6 e 12 anos; mais tarde, entre os anos de 1880 e 1936, serão os indivíduos com idade entre 4 e 14 anos. Essa mesma idade será tocada até por volta de 1959, quando então - e até os dias de hoje - temos indivíduos entre 3 e 17 anos. Podemos afirmar, assim, que, no mínimo uma vez por semana, mais de $80 \%$ de uma faixa etária que frequenta a escola nos dias atuais até por volta dos 18 anos de idade, ${ }^{3}$ está exposta a essas representações.

Esta pesquisa foi realizada a partir da análise de manuais escolares de moral e de higiene pertencentes ao acervo do Centre d'Etude et de Recherche en Histoire de l'Education (CEDRHE) de Montpellier (França), arquivo que guarda mais de 25.000 manuais escolares desde o início do século XIX e que nos serviu de base. Um primeiro trabalho de análise permitiu validar a ideia de recortes temáticos importantes entre os manuais de moral e de higiene, por exemplo, no que concerne a questões ligadas à limpeza, à prescrição de exercícios físicos ou, ainda, à nutrição. Outro tema que surge de maneira clara nesses manuais refere-se às bebidas alcoólicas e todas as inúmeras questões decorrentes de seu uso, e que se fazem presentes de maneira robusta no interior de suas páginas.

Nosso estudo foi realizado a partir da análise de um total de 342 manuais, sendo 234 de moral e 108 de higiene. Esses manuais eram destinados tanto à escola

2. Estudos recentes como o que realizou Bernard (2007) mostram, por exemplo, a eficácia e a potência da iconografia dos manuais de ciências da vida e da terra para a constituiç̧ão das representações coletivas referentes ao corpo. No que se refere ao aparelho genital feminino, por exemplo, os entrevistados, de forma massiva, representam essa parte do corpo exatamente como ela é apresentada nos manuais escolares.

3. Essa faixa de idade de 18 anos é significativa, pois coincide com o que, na França, se chama baccalauréat, o exame que vai permitir o ingresso na universidade; no Brasil essa faixa de idade também corresponde, em tese, ao término do ensino médio e à possibilidade de se submeter ao vestibular para ingresso no ensino superior. 
primária quanto à secundária, às classes da pequena infância, aos liceus e, ainda, às Escolas Normais. Nossa pesquisa considerou, também, as classes destinadas especificamente às meninas e aos meninos no início do século $X X$.

\section{OS MANUAIS E SEU CONTEÚDO}

De um modo geral, os manuais de moral aqui analisados contêm em sua estrutura uma parte intitulada: "os deveres voltados a si mesmo", parte que, na maioria das vezes, apresenta uma subdivisão que tem como título: "os deveres voltados ao nosso corpo". Esses foram os elementos especificamente estudados e analisados, uma vez que todos, sem exceção, tratam de preceitos corporais e organizam um sistema de controle bastante preciso e meticuloso.

No que diz respeito aos manuais de higiene, tudo nos parece bem mais simples, uma vez que o essencial de seu conteúdo já é consagrado ao corpo. Em nosso estudo, então, excluímos os capítulos que tratavam da arquitetura das casas e dos detalhes da posição das janelas e portas em relação ao sol, assim como o que diz respeito à água encanada e ao esgoto, entre outros elementos que não os especificamente "corporais", em sentido estrito.

Aquilo que impressiona e surpreende é, em todo caso, a recorrência e a constância dos temas presentes praticamente ao longo de um século, o que revela, sem dúvida, a sua eficácia. Não menos surpreendentes são as transformações que se operam em termos de método de apresentação desse conteúdo e de sua especificidade em função do nível dos alunos, ou em relação ao período estudado.

Os temas mais presentes são os seguintes: a) para os manuais de moral encontramos de modo recorrente a ideia de preservação do corpo expressa em temas como o suicídio, as mutilações diversas, a preguiça, a prudência, a gula, a cólera, o trabalho, a coragem, a temperança e a sobriedade; b) para os manuais de higiene encontramos as prescrições relativas à limpeza corporal, mas, também, ao equilíbrio alimentar e à respiração; c) temas comuns aos dois tipos de manuais analisados são: a atenção voltada ao corpo, a temperança, a sobriedade, o alcoolismo e a embriaguez, a limpeza, o trabalho, o exercício físico e, mais tarde, o esporte.

A seguir apresentamos os diferentes temas e as mudanças, sobretudo de método e de forma, que se operam ao longo do período analisado.

\section{OS GRANDES TEMAS DOS MANUAIS: O SUICÍDIO E AS MUTILAÇÕES}

Iniciaremos com o tema do suicídio, que, embora não encontrado em todos os manuais, apresenta aspectos importantes para a análise aqui empreendida. As 
obras destinadas às crianças pequenas, em especial aquelas voltadas às salas dos asilos, aos jardins de infância e mesmo aos cursos preparatórios dos instrutores não tratam do suicídio em suas páginas, talvez pelo medo de chocar os leitores e aqueles que trabalham com essa faixa de idade. Porém, o contrário vai se produzir a partir dos cursos elementares e mesmo em relação às classes dos liceus, em que encontramos, em todos os documentos, uma menção a esse interdito. Constatamos, contudo, que a presença do tema - suicídio - se torna rara a partir de 1923, momento em que se suprime dos programas escolares os deveres voltados a Deus e, por consequência, e um pouco mais tarde, por volta de 1926, também dos manuais escolares. Haveria então, de certa maneira, correlação entre esses dois fatos, ou, se não há correlação, haveria, ao menos, conjunção.

Sem dúvida, a tese de Durkheim sobre o suicídio, publicada em 1897, teve um peso sobre a presença desse tema nos manuais, sendo citada com frequência a partir do começo do século $X X$. Seria importante, contudo, salientar que os manuais existentes em períodos anteriores à publicação dessa tese já destinavam um capítulo ao tema do suicídio e apoiavam-se em trabalhos mais antigos, especialmente naqueles de moral religiosa. Caberia retomar aqui que após o concílio de Braga, ocorrido entre os anos $56 \mathrm{I}$-563, subtrair-se à vontade divina suprimindo a si mesmo passa a ser totalmente condenado pela Igreja católica. No século IX, o anátema é pronunciado contra os suicidas, que passam a não ter direito a um sepultamento segundo os ritos religiosos e, sobretudo, o direito às preces destinadas à saúde de suas almas. Esse ponto de sujeição corporal repousa, pois, sobre os fundamentos católicos ou, mais amplamente, cristãos. Contudo, é importante sublinhar que na França a escola é massivamente republicana, laica e que a separação entre as Igrejas e o Estado ocorreu a partir de 1905.

Nos manuais de moral estudados, pudemos perceber que, por exemplo, um suicídio glorioso cometido em razão do bem comum é tolerado. Um exemplo recorrente nesse sentido é aquele do Cavaleiro D'Assas, gritando forte: "Venha a mim Auvergne, ${ }^{4}$ estes são os seus inimigos!", ou seja, em detrimento da própria vida, em tempos de guerra e pelo cuidado com os outros, esse suicídio é citado em numerosos manuais como exemplar. De modo inverso, por meio do interesse da Nação, todas as mutilações são proscritas e consideradas como um traço de covardia, vileza, infâmia. Esse tema será cada vez mais presente à medida que se aproxima a guerra de 1914-1918. A passagem abaixo destaca de modo claro o clima belicista vivido naquele momento.

4. Trata-se aqui do Batalhão de Auvergne, batalhão originário de uma região da França. 
[...] conta-se nos vilarejos que durante um sorteio um mau sujeito que desejava escapar do recrutamento do serviço militar cortou dois dedos com a finalidade de fazer com que o Conselho de Revisão o declarasse impróprio para o Serviço Militar. Este infeliz foi preso [...] O suicídio não é mais que desnudamento fatal de uma vida criminosa, a falta suprema que encerra uma longa série de faltas. $\bigcirc$ amor à vida não abandona aqueles que usaram mal a vida. (COMPAYRÉ, I895, p. 120).

Outro exemplo, bem mais breve, também pode ser aqui tomado como ilustrativo dessa máxima: "[...] A vida é um combate: vergonha a quem foge dele!", "O suicídio é um roubo feito ao gênero humano" (ROUSSEAU apud DEVINAT, 1890, p. 50).

Progressivamente, após a supressão dos deveres voltados a Deus dos programas de 1926, o tema desaparece para dar lugar, bem mais tarde, por volta dos anos de 1960, à questão da eutanásia. Nesse caso, as respostas são as mesmas que para o suicídio. A partir desse momento, toda morte provocada e não acidental é descrita como uma afronta ao gênero humano e não mais a Deus. Este tema, contudo, não se faz presente nos manuais de higiene, cujas páginas acolhem a luta contra a doença e a resistência à dor física e psíquica.

É importante registrar que os protagonistas das cenas de suicídio que ilustram os manuais são sempre os operários, e mesmo os desempregados, aqueles considerados como sem coragem de afrontar as dificuldades que enfrentam. Tomamos como exemplo o relato do suicídio de Genouillet, em um manual de 191। (DEVINAT, 191 I, p. 108-109), que é particularmente ilustrativo desse tema. Genouillet é um desempregado cuja família é apresentada num quadro de grande penúria em que a fome devasta seus membros; Genouillet, não suportando mais ver essa tragédia diante de si, coloca um fim em sua vida, enforcando-se. Ele é descrito, então, como aquele que deixa a sua família em uma situação ainda maior de sofrimento. Sua esposa, ao contrário, é descrita como uma mulher corajosa que recusa a solução extrema do suicídio, decidindo lutar pela sobrevivência de seus filhos.

Vê-se aqui que o tema do suicídio carrega, de maneira profunda, todo o peso do dogma judaico-cristão. Dois elementos estão presentes nesse último exemplo: I) a interdição dogmática do suicídio, ou seja, o homem não pode colocar um fim naquilo que foi criado por Deus; 2) a compaixão suscitada pelo leitor, uma vez que essa "lição" é sugestivamente ilustrada por imagens fortes de penúria e miséria humanas.

A partir do início do século XX e do fim da I Guerra Mundial, o suicídio será descrito igualmente como uma falta de consideração para com a sociedade, que se vê, de um lado, privada de sua força produtiva e, de outro, de um soldado para a guerra. ${ }^{5}$

5. Neste período a França possuía uma das mais baixas taxas de natalidade de toda a Europa. 
A leitura desses manuais permite inferir que no momento em se opera um distanciamento religioso, surge uma França cada vez mais internacionalista, operária e republicana. Conforme os dados de Taine, em I894, uma mulher em cada 12 e um homem em cada 50 possuíam uma prática religiosa regular. No mesmo sentido, o desenvolvimento exponencial da franco-maçonaria antidogmática desempenha um papel importante, fazendo com que esse tema se torne distante das preocupações mais prementes.

\section{A LIMPEZA E A HIGIENE CORPORAL}

A tese da limpeza corporal e da higiene, num sentido mais amplo, está presente em todos os tipos de manuais, mas, para aqueles específicos de higiene, essa tese surge ligada à ideia de saúde e, muito rapidamente, ela também fará referência aos micróbios. Assim, a tese da limpeza não pode mais ser dissociada da "higienização" das cidades, algo que se afirma na Paris do Barão Haussmann nos anos de I860. A ideia de higienização, aliás, tem um duplo sentido, uma vez que, para Haussmann, se trata, também, de limpar a cidade de seus fermentos revolucionários situados na zona leste parisiense. Poderíamos afirmar aqui, e sem qualquer receio de uma aproximação anacrônica, que essa tese parece ainda atual, considerando afirmações feitas pelo ex-presidente da República francesa, Nicolas Sarkozy (2007-20 I 2), quando afirmou a necessidade limpar as periferias das cidades, usando "jatos de água". ${ }^{6}$

No momento em que evocamos essa tese da limpeza, não seria possível esquecer as transformações das condições de vida urbana. Com efeito, o desenvolvimento e fornecimento público de água encanada, sem dúvida, permitem a multiplicação dos locais destinados aos banhos públicos. Em Paris, no ano de 1850 , havia um total de 125 locais à disposição da população e, desse modo, cerca de 950.000 parisienses tomam mais de dois milhões de banhos públicos nesse ano, sendo em média 2,23 banhos por habitante ao ano. Esses números, contudo, são relativos, e as pesquisas médico-sociológicas indicam que, em 1962, apenas 29\% dos lares franceses dispunham de uma banheira ou de um chuveiro, taxa que será de $48 \%$ em 1968 e de $85 \%$ em 1990. Em todo caso, vejamos o que propõe um manual de 1882 em relação à higiene corporal feita com água:

Nós dividiremos, para maior clareza, estas abluções em duas categorias: I- as que se limitam ao rosto e as mãos; 2 - as que tomam o corpo inteiro [...] $\bigcirc$ hábito de se lavar cada manhã o rosto e as mãos é generalizado [...] Esta toalete matinal deve ser feita com

6. Em francês, literalmente, a expressão pronunciada por Nicolas Sarkozy (2007-20 I2): "nettoyer au karcher". 
bastante água e esta água deve ser fria. Convém agregar, ao menos uma vez por semana, uma lavagem da cabeça, com água fria se os cabelos são curtos e com água morna se eles são longos. (PÉCAUT, I890, p. 100).

Nos inúmeros manuais analisados, ${ }^{7}$ foi possível encontrar ao longo de todo o século XIX essa prescrição: uma toalete sumária todos os dias e um banho, ou uma lavagem completa, uma vez por semana, ou a cada 15 dias. Entretanto, devemos insistir sobre dois aspectos: o primeiro deles diz respeito às mudanças prescritivas no que se refere ao período estudado; e o segundo sobre o efeito na vida individual e social da associação entre uma toalete que inclui um cuidado com a limpeza corporal, e outra que inclui a prática do exercício físico já na década de 1950 e, mais tarde, a prática do esporte.

Não podemos mais dissociar limpeza corporal, como verificamos no plano dos manuais de moral, de "pureza da alma", e poderíamos mesmo acrescentar aqui a ideia de purificação da raça. Admitindo com Mary Douglas (1966) que o corpo é a metáfora do social, compreendemos que sua limpeza exacerbada, que conduz à ideia de "pureza" da alma ou da raça, dificilmente pode ser dissociada dos fantasmas sociais de pureza da raça presentes em países europeus ao longo do período entreguerras. ${ }^{8}$

Porém, existe um grupo humano que é sempre tomado como aquele que deve ser mais purificado: os operários. Tanto nesse caso como naquele que se refere ao suicídio, os exemplos dados são sempre tomados do meio operário, dos camponeses, e jamais da burguesia. Evidentemente poderíamos atribuir esse estereótipo às condições de vida, mas isso não nos parece assim tão simples. Limpar, lavar a classe operária, é também purificá-la, em alguma medida, dos ideais revolucionários internacionalistas, ideais contrários, portanto, a uma República apaziguada que desejava a burguesia francesa. Reencontramos nesse conjunto de ideias acerca da limpeza os mesmos exemplos do suicídio, cuja recorrência era dada por Genouillet. Entretanto, no mesmo manual (DEVINAT, | 9 | | , p. | | 3- | | 4) em que vemos descrito o caso do suicídio de Genouillet, um suicídio não glorioso, vemos também o caso de Berthe Longuet, uma jovem pobre que poderia tanto ser operária como camponesa, e o manual não traz qualquer precisão em relação à sua condição específica. $\bigcirc$ que o manual destaca é a aparência dessa jovem, descrita como muito suja e de quem todos desejavam se afastar em razão da imundície acumulada em seu corpo e em suas roupas, da sujeira que ela exalava.

7. Por exemplo, GALTIER-BOISSIERE. Notions élémentaires. Hygiène pratique. Paris: A. Colin, 1921. p. I31; BOULET,

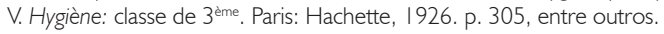

8. Pensemos de modo mais especifico na Alemanha com o advento do nazismo e na ltália com o fascismo. Poderíamos, assim, pensar que lavar é também "purificar". 
Um manual de 1888 resume bem os fundamentos dos micro-poderes exercidos pelos manuais de moral e de higiene, que revelam de maneira clara o funcionamento de um sistema comum, de um discurso homogêneo indicando que "[...] Seguir as leis da higiene, ser limpo e equilibrado, é tornar-se mais apto a preencher todos os deveres: ter um corpo são é um dos meios que conduzem a ter uma alma sã" (LALOI; PICAVET, I 888, p. 257). Outro manual de I 890 também sublinha a importância da limpeza, afirmando ser ela "[...] um dos caracteres do homem bem educado, do homem digno dele mesmo e da sociedade [...] A criança limpa é bem vista em todos os lugares e por todos: por ela mesma, na escola, em todas as reuniões onde pode ir" (CAZES, 1890, p. 55-56).

De certo modo, a luta pode mesmo aproximar-se de uma cruzada purificadora, conforme podemos ler no extrato que segue, retirado de um manual de 1918:

[...] É necessário pregar a cruzada das mãos limpas dizia um publicista, [...] seria necessário pregar a cruzada das epidermes limpas. [...] voluntariamente, a imundície fisica anda de mãos dadas com a grosseria intelectual e moral, e limpar as epidermes não é, talvez, menos útil que trazer luz aos cérebros. (ANCEL; BOUCHER, 1918, p. 121).

Um aspecto que cabe destacar, ainda, em relação à limpeza e à higiene presente nos manuais, é a mudança das estratégias de aprendizagem. Assim, se desde fins do século $X I X$ e início do século $X X$ ganham espaço as injunções e a aprendizagem de versos cantados ou mesmo de recitações sobre o tema, após a Segunda Guerra Mundial uma transformação radical desse formato se opera, e a injunção "você deve" ou "nós devemos" passa, muito rapidamente, para o indivíduo, quando então passamos a ler: "eu devo". Tomemos aqui um exemplo dessa mudança que ocorre no fim dos anos de 1940 e início dos anos de 1950, no extrato selecionado de um manual do período:

[...] I. Eu experimento um grande prazer em ser limpo. Cada dia eu cuido do meu rosto, de minhas mãos, de meus dentes, de meus cabelos. Eu lavo minhas roupas, meu chapéu, meus sapatos; eu tomo banho com frequência. A falta de limpeza me inspira repugnância. Eu não gosto de apertar uma mão suja e nem de beijar um rosto mal lavado [...]. (BOURCEAU; FABRI, 1949, p. 200).

A partir dos anos de 1960, essa individualização e personalização ética são duplicadas por uma injunção hedonista: ser limpo dá prazer. Um manual de 1964 sublinha essa afirmação, apresentando aos leitores o "prazer da ducha" em um texto de Colette C., cujo conteúdo é quase erótico, e apresentado ao lado de uma foto de crianças que brincam durante o banho: 
Hoje é quinta-feira, o dia em que eu tomo minha ducha, e eu estou muito feliz. Eu me dispo rapidamente e abro a torneira. Sofrimento!!! A água está queimando ! Eu manobro a torneira: a água torna-se fria! Enfim, eu consigo regular a temperatura da ducha. Então, que prazer sentir esta chuva fina que cai sobre mim cujas milhares de pequenas agulhinhas pinicam a minha pele! A água deliciosamente morna escorre ao longo de minha coluna vertebral. Prazer também de me ensaboar vigorosamente com um sabonete delicadamente perfumado. Por vezes ele escorrega de minhas mãos, eu o agarro e recomeço este pequeno jogo. Aágua desliza por sobre meu corpo quando eu me enxáguo, ela entra em meus olhos, em minhas orelhas, e eu rio sozinha. Eu fecho a torneira e me chacoalho cuidadosamente fazendo cair as mil gotinhas que brilham sobre a minha pele como pérolas. Enfim, eu me enxugo cuidadosamente. Eu me sinto bem, eu tenho vontade de cantar. É com pesar que eu me visto novamente. (VILLARD, 1964, p. 6).

O tema da limpeza permite observar como o sistema de controle presente nos manuais sofre mudanças em termos pedagógicos e didáticos, mas, também, como o biopoder ${ }^{9}$ se reorganiza e penetra cada vez mais na intimidade pessoal, tornando-se uma apropriação individual e não mais um controle moral externo. Essa interiorização e individualização não significam, todavia, que o indivíduo seja mais livre aos olhos das injunções higiênicas e morais, significa simplesmente que as pessoas se apropriaram desses discursos ou, ao menos, os autores que os escrevem supõem que essa apropriação tenha ocorrido. Vemos aqui, aliás, os progressos da didática e da pedagogia como sistemas de controle, uma vez que o aluno é implicado, pelo viés do prazer suscitado, no próprio sistema de controle. As grades da prisão não estão mais no exterior, elas foram internalizadas pela criança, pelo aluno, pelo adulto.

\section{A SOBRIEDADE}

Este tema está presente tanto nos manuais de moral quanto nos de higiene, mas ao longo do tempo é possível perceber uma mudança de conotação em seu emprego. Assim, se no início do período aqui estudado a sobriedade é sinônimo de temperança no que se refere à nutrição, ao longo do tempo ele passa a significar temperança em relação à ingestão de bebidas alcoólicas. Evidentemente, podemos ser surpreendidos pelo fato de que essa noção - sobriedade -, presente no domínio da nutrição, possa ser projetada sobre a massa da população, notadamente ao fim do século $X I X$ e início do século $X X$, pois nos bairros operários da região leste

9. Ver especialmente os trabalhos desenvolvidos por Michel Foucault no primeiro volume da História da sexualidade, intitulado "A vontade de saber" e também na transcrição de seu curso de 1975-1976 no College de France e publicado no Brasil em 1999, sob o título de "Em defesa da sociedade", além de "O nascimento da biopolítica" publicado em 2004 e no Brasil em 2008. 
de Paris os pequenos camponeses sofriam muito mais pela miséria e escassez de alimentos e mesmo pela fome, do que pela ingestão excessiva.

A noção de temperança, assim, parece ser dirigida mesmo à burguesia por meio de uma projeção da classe operária. Em todos os casos, a temperança é uma virtude cristã cardeal, e a gula é um dos sete pecados capitais. Compreendemos, pois, e ainda uma vez mais, sobre qual base se apoia a moral e sobre quais fundamentos repousa o discurso higiênico dos manuais. Naqueles de higiene, sem dúvida, está também presente uma moral. Vejamos aqui um exemplo do tipo de parábola ilustrativa presente nos manuais que é apresentada aos alunos mais velhos:

[...] Ouçam a história do Vénetien Cornaro [...] ele morreu aos 99 anos. Entretanto, por volta de seus 35 anos ele esteve muito fraco, doente a tal ponto que os médicos o consideraram como um caso perdido, se ele não mudasse de regime. [...] A partir daquele momento, ele passa a comer diariamente uma pequena quantidade de comida, sem variar jamais doze gramas de alimentos: pão, sopa, ovos, carne ou peixe, e I 4 gramas de vinho. É graças a este regime que ele viveu dos 35 aos 99 anos, sem doenças e sem qualquer enfermidade [...]. (COMPAYRÉ, I885, p. |22-123).

Caberia aqui sublinhar a estabilidade, ao longo do tempo, de uma máxima que retorna como uma antífona nos manuais acerca da comida, em que se lê com frequência que "é necessário comer para viver e não viver para comer". (CAZES, 1890, p. 53).

Assim, voltamos a refletir sobre a noção de sobriedade e de seu lugar nos manuais analisados ao longo do tempo. A partir dos anos de 1930, essa noção volta-se cada vez mais ao consumo de bebidas alcoólicas e não tanto de comida, com um conteúdo dirigido mais enfaticamente aos alunos mais velhos, do sexo masculino, ou às meninas. $O$ alcoolismo, ou o consumo exagerado de bebidas, é, assim, destacado como oposto à temperança. Nós nos deparamos com o deslocamento dessa noção em um adágio de 1926: "[...] A temperança é a virtude moderadora de nossas necessidades e de nossas paixões que nos distancia de todo o excesso; a sobriedade é a temperança na bebida e na comida". (FAYE, 1926, p. I5).

Constatamos nessa citação que é bem a questão da virtude cardeal - temperança - que é central. Muito mais do que uma questão de higiene trata-se, aqui, de uma questão de moral cristã.

\section{EMBRIAGUEZ, ALCOOLISMO, GULA}

A gula é o pecado capital que se opõe à virtude cardeal da temperança. Ela está presente nos manuais de higiene e de moral destinados aos mais jovens e substitui, nesse caso, o alcoolismo e a consequente embriaguez. 
Ainda uma vez mais, entretanto, podemos nos perguntar qual era a realidade de uma possível apresentação do pecado capital da gula para os mais jovens, filhos de operários e camponeses, ao olhar dos trabalhadores que ganhavam seus salários por dia trabalhado- os diaristas- no início do século $X X$ e das famílias constituídas de 5 a 9 filhos. Na realidade, os manuais colocavam em evidência o que era absolutamente impossível para os pobres.

Podemos pensar que a pequena burguesia que redige os manuais ou os burgueses que editam os programas dirige essas injunções, antes de tudo, a eles mesmos ou aos seus próprios filhos, muito mais do que à classe operária e camponesa, ambas muito pobres. Não podemos esquecer que o açúcar, por exemplo, custava muito caro, e que os operários das cidades utilizavam muito mais o mel ou outros adoçantes com preços mais acessíveis. Mesmo assim, é à classe operária que são atribuídos a gula e, ao mesmo tempo, o vício relativo às bebidas alcoólicas, e a consequente embriaguez. Os exemplos apresentados vão sempre nesse sentido, e aqui vamos ilustrá-los com aquele encontrado em um manual de 191 I, em que surge o Sr. Bourgoin, ${ }^{10}$ um burguês bem sucedido, e o Sr. Duchard, homem oriundo de um meio popular. O Sr. Bourgoin surge ali como homem bastante controlado (temperado certamente!) no domínio do álcool e da comida, apesar de dispor de todos os meios em abundância para esse consumo. Ao contrário, o carpinteiro Duchard, homem oriundo de um meio popular, é apresentado como um bêbado notório e como alguém que, quando embriagado, é capaz de agredir sua mulher, seus filhos e, no momento seguinte, arrepender-se amargamente.

Apesar dos exemplos moralizantes, e especificamente no que diz respeito ao alcoolismo, seria necessária uma análise mais apurada, sobretudo, seria desejável confrontar o consumo de bebidas alcoólicas com o real nível de vida dos operários. Ora, no momento em que se observa o nível de salário dos trabalhadores pagos em jornadas diárias, nos parece claro que esse trabalhador não poderia comprar a quantidade de bebida que é, em geral, atribuída aos operários ou a certos profissionais "pobres", o que corresponde a algo em torno de 3 litros de vinho por dia. $\bigcirc$ mesmo raciocínio é válido, evidentemente, para o consumo de doces e do açúcar para um comportamento voraz em relação à comida e à bebida. "

Ao contrário, é necessário sublinhar que as doses de álcool "puro" propostas pelos higienistas que redigem os manuais mudam, consideravelmente, ao longo do tempo. Um litro de vinho por dia parece razoável para um operário ou um

10. O nome, Bourgoin, evidentemente foi inventado como nome próprio e sua grafia aproxima-se, bastante, daquela da palavra burguês. Esse exemplo pode ser encontrado em Devinat (|9|1).

11. Os dados referentes às afirmações neste parágrafo podem ser encontrados em Elleinstein (1980, p. 182, p. 229). 
camponês no começo do século, enquanto após a Segunda Guerra Mundial somente um terço de litro é aceitável pelos higienistas e moralistas da época.

Seria necessário sublinhar algo que não pode, em nosso entendimento, ser negligenciado no plano sanitário, e que provavelmente incita os higienistas e moralistas que redigem os manuais a valorizar seja o consumo de cidra, seja o de uma bebida fermentada feita de pera, do vinho ou da cerveja, desde fins do século XIX e mais ou menos até a Primeira Guerra Mundial (|9|4-19|8). A água não é, ainda, uma bebida que apresente qualidades sanitárias adequadas até mais ou menos a década de 1920.

A última epidemia de cólera que assola a França, a Itália e mesmo a Inglaterra ocorre exatamente antes da Primeira Guerra Mundial, e ela fará milhares de mortes. Sabemos bem que essa epidemia é veiculada, essencialmente, pelas águas não tratadas, pelas águas poluídas, portanto, bebidas como o vinho, em torno de $7^{\circ}$ a $8^{\circ}$ graus, a cidra, a bebida fermentada de pera, a cerveja, não comportam tal risco para a saúde pelo simples fato de serem produzidas por um processo de fermentação alcoólica e, no caso do vinho, da cidra e da bebida feita a partir da pera, de seu líquido ser oriundo da fruta e não da água. A água ameaça e, portanto, compreendemos bem que do ponto de vista higiênico, o consumo de bebidas como as citadas, mesmo sendo alcoólicas, pudesse ser aceito e mesmo reputado no começo do século $X X$. Entretanto, quando são mencionados os excessos em qualquer nível e instância, observamos que é sempre a classe operária que será descrita como aquela mais fortemente sujeita aos excessos, seja no âmbito da bebida, seja naquele da comida.

O pano de fundo, em todos os casos, permanece sendo sempre moral, conforme um manual de 1933 que afirma: "[...] Não é proibido fazer uso de atrativos e de prazeres que a vida oferece, é necessário somente fazer com que essas satisfações e atrativos não se tornem tiranos [...]". (GUY-GRAND, 1933, p. 76).

Para os temas do alcoolismo, da temperança, da embriaguez e da gula, muitos exemplos, tal qual para os temas precedentes, retornam de maneira recorrente. Aquele de Alexandre, o Grande, que mata seu amigo em um estado de cólera causado pela embriaguez, ou, ainda, o exemplo para os estudantes mais jovens, do caso do Rei Gourmandot, ${ }^{12}$ que morre de indigestão. Podemos, evidentemente, encontrar inúmeras máximas, mais surpreendentes ainda ou mesmo mais edificantes. ${ }^{13}$ Tanto para o alcoolismo quanto para a embriaguez ou a gula encontramos a descrição de

12. Gourmendot significa um pequeno comilão, um pequeno guloso.

13. “[...] Sabeis vós, diz Lamennais, o que bebe este homem em seu copo, hesitante, que vacila em sua mão trêmula de embriaguez? Ele bebe lágrimas, sangue, bebe a vida de sua mulher e de seus filhos [...]" (BOYER, 1895, p. 128). 
uma espécie de algoritmo nos manuais de higiene, mas, sobretudo, de moral: o alcoolismo ou a embriaguez, assim como a gula, podem conduzir ao roubo e/ou à violência, e, mesmo à morte. Assim, tocar na engrenagem de um desses pecados capitais não pode conduzir senão a uma experiência fatal, experiência que revela onde se alojam as injunções dos manuais de moral e de higiene.

\section{A CÓLERA, A DOÇURA}

Neste texto não desenvolveremos de modo mais amplo este tema, uma vez que nos parece já bastante claro que tanto a doçura quanto a cólera estão associadas à embriaguez ou ao alcoolismo. Para os mais jovens, entretanto, trata-se de um tema que pode ser dissociado e considerado, então, como um traço do caráter que convém corrigir. É importante observar, simplesmente, que a cólera é um dos sete pecados capitais para a religião católica. Contudo, é importante sublinhar que os manuais de higiene e de moral são republicanos e laicos, mas, mesmo assim, ecoam de modo intenso valores religiosos, virtudes cardeais, e mesmo os sete pecados capitais. A cólera, em todo caso, é considerada defeito, do qual devemos nos libertar o mais cedo possível e, ao contrário, a doçura é virtude que convém desenvolver, tanto quanto o autocontrole. A doçura é sempre descrita como uma virtude particularmente útil para uma mulher, tema que é, aliás, ao lado do esporte, um dos raros em que os manuais distinguem mulheres e homens, meninos e meninas. Com frequência vemos nas páginas dos manuais a associação entre cólera e feiura, e um manual de 1920 resume bem o que acabamos de destacar: "[...] Enquanto a cólera dura, aquele que a manifesta não é mais seu próprio mestre; ele perde sua razão, sua consciência e as qualidades que o distinguem de um bruto. $\bigcirc$ homem em cólera é rebaixado ao nível do animal feroz". (BRÉMOND; MOUSTIER, 1920, p. |33-134).

\section{ORDEM E DESORDEM}

Se o corpo é a metáfora do social e, para os manuais, a metáfora do espírito, compreende-se que toda desordem corporal ou espacial testemunha uma desordem da alma e da pessoa. Ter suas coisas em ordem é, pois, de certa maneira, ser socialmente ordenado. A partir da análise que procedemos dos documentos consultados, é possível afirmar que a desordem surge bastante próxima à cólera e, em sentido inverso, a ordem se aproxima da doçura.

Mary Douglas, ainda uma vez mais, permite captar, nesse caso, a metáfora do social. Aquilo que é prescrito para o ambiente corporal imediato é bem a ordem 
da sociedade, pois o problemático, sempre, é o que não se pode classificar, ou, ao menos, o que não sabemos como e onde classificar. A autora também assinala que aquilo que se mostra como um problema para todas as instituições é a desordem, esse estado que contém em si um sentido do que é inclassificável. Entre outros exemplos, pode-se tomar aquele dado pela autora em relação às coisas, ou as funções corporais, que apresentam uma consistência de viscosidade, e de como esse estado da matéria incomoda de modo excessivo muitos ocidentais, uma vez que se trata do inclassificável, daquilo que não é nem líquido, nem sólido. A autora oferece, ainda, inúmeros outros exemplos, notadamente no que se refere à proibição de certos alimentos presentes no livro de Levítico da Bíblia Sagrada, alimentos inclassificáveis para uma população de colhedores e caçadores do século $X$ antes da era cristã. A desordem corporal e sua possível proscrição e interdição não se inscreve nessa lógica de uma possível classificação do real, assim como da lógica dos controles e, sobretudo, do controle das "classes perigosas".

\section{A CORAGEM FÍSICA E MORAL}

A coragem faz parte dos valores cardeais cristãos, e nos manuais ela é bastante valorizada, sendo com frequência trazida à cena para inúmeras reflexões, entre outras, em relação ao suicídio. $O$ interessante é observar a maneira como a coragem aparece nos manuais, ou seja, de maneira racionalizada e temperada para que não seja confundida com um suicídio cometido pelo excesso de impetuosidade. É assim que os manuais afirmam a necessidade de ser corajoso, mas não temerário e nem temido.

\section{O DEVER DO TRABALHO, A PREGUIÇA}

É nessa mesma óptica que a preguiça será proscrita e o trabalho valorizado. Não podemos esquecer que a preguiça é um dos sete pecados capitais, o que indica bem a marca do dogma cristão nos manuais, genericamente, "laicos" e por vezes mesmo anticlericais, o que é, no mínimo, paradoxal.

O trabalho, na religião católica em sua vertente mais radical, notadamente para a Opus dei, é santificado, mas, ao mesmo tempo, de maneira bastante paradoxal, ele é uma maldição infligida ao Homem em consequência do pecado original. Entretanto, nós não identificamos esse paradoxo nos manuais que valorizam da mesma maneira o trabalho manual e trabalho intelectual. Outro traço comum e bastante visível em todos os manuais consultados é a crítica contundente em relação ao ócio, sendo que a preguiça surge em suas páginas como "a mãe de todos os vícios". 
Dos manuais analisados, raros são os que realizam uma crítica do trabalho alienado e alienante, sobretudo do trabalho repetitivo de tipo taylorista junto aos alunos; os manuais que fazem essa crítica inscrevem-se em uma óptica marxista. ${ }^{14}$ O trabalho é, sem dúvida, assim concebido na maioria dos manuais analisados:

\begin{abstract}
O trabalho, manual ou intelectual, é um dever para o homem: ele permite a subvenção de suas necessidades e a de sua família, ele o enobrece e lhe dá prazer e saúde; a ordem e a economia conduzem ao bem-estar e mesmo à riqueza. $\bigcirc$ preguiçoso que vive de esmolas, o ocioso que usa para as suas despesas inúteis e corruptoras a fortuna que seus pais the deixaram, perde a dignidade do homem e são nocivos à sociedade da qual eles fazem parte. (LALOI; PICAVET, I888, p. 260).
\end{abstract}

A maioria dos manuais analisados concebe o trabalho como uma atividade humana que nos torna superiores aos animais. Para esta discussão, a fábula de Lafontaine, O lavrador e seus filhos, ${ }^{15}$ é frequentemente utilizada. Lembremos que essa fábula apresenta claramente uma moral do trabalho, à medida que o lavrador, personagem central, chama os filhos antes de morrer e lhes diz que "os bens que tinha enterrados estão na nossa vinha"; os filhos, então, se lançam a revirar a terra para procurar os bens, ou, mais precisamente, um imaginário "tesouro" que nunca encontram e que os faz continuar a trabalhar a terra que, assim "trabalhada", não cessa de dar bons frutos que "enriquecem" os filhos do lavrador. $O$ trabalho surge, nessa fábula, como o verdadeiro tesouro, como o maior tesouro.

\title{
O EXERCÍCIO FÍSICO E O ESPORTE
}

O exercício físico e, mais tarde, o esporte, já a partir de 1950, desempenham o mesmo papel que o trabalho. O adágio de Juvenal, extraído dos Sátiros, retorna como um leitmotiv em todos os capítulos consagrados ao exercício físico que sucedem, na maioria das vezes, os capítulos sobre o trabalho e a preguiça: mens sana in corpore sano.

A metáfora do corpo como invólucro da alma está presente no conjunto dos manuais e, evidentemente, nesses capítulos que, entretanto, nos permitem observar uma mudança bastante evidente acerca desse aspecto.

O único exercício físico que os manuais de higiene e de moral produzidos entre 1880 e 1940 consideram bom é aquele feito com moderação, equilíbrio, um exercício que surge exatamente para compensar os estudos e reequilibrar o

14. Por exemplo, RAYOT, E. Leçons de morale pratique. Paris: Delaplane, 1895.

15. Utilizamos a versão em português, DE LA FONTAINE, J. Fabulas. São Paulo: Landy, 2004. v. I. p. I65-166. traduzida por Couto Guerreiro. 
psiquismo. Após 1945, é o esporte o conteúdo que vai substituir esse exercício físico moderado, e ele será dirigido, primeiramente, aos meninos e depois, progressivamente, também às meninas.

A partir de 1945, a ideologia e os valores veiculados mudam radicalmente. Não é mais o exercício físico moderado, equilibrado e regular que é valorizado, mas a "ultrapassagem de si", não é mais mens sana in corpore sano, mas mens fervida in corpore lacertoso ${ }^{16} \mathrm{ou}$, ainda, citius, altius, fortius. A ideologia esportiva do excesso e constante ultrapassagem de si tomam o lugar da ideologia sanitária de um equilíbrio médio e benfazejo.

O esporte é o elemento excepcional dos manuais, o exemplo que refuta a regra pela qual, após os anos de 1950, a temperança não é mais valorizada e, bem ao contrário, trata-se a partir de então da intemperança, do prazer e dos excessos, da ultrapassagem de si.

\section{AS GRANDES REGRAS DE CONSTITUIÇÃO DOS DISCURSOS DOS MANUAIS ESCOLARES DE HIGIENE E DE MORAL}

Inúmeros aspectos constituem a ordem do discurso dos manuais de moral e de higiene. Uma regra pedagógica e didática que surge de maneira clara em relação ao conteúdo dos manuais destinado aos mais jovens, diz respeito ao conteúdo, muito mais ilustrado e apresentado por imagens e desenhos que ocupam quase todo o espaço. Ali o texto escrito passa para uma posição quase secundária. Esse mundo de imagens traz paralelamente histórias que dizem respeito à vida cotidiana desse público leitor, constatação que é verdadeira praticamente para todas as épocas.

No que se refere ao conteúdo, poderíamos afirmar que as meninas são pouco discriminadas em relação aos meninos, a não ser nas questões relativas à limpeza, uma vez que elas devem ser sempre, muito mais limpas que eles. $\bigcirc$ mesmo pode ser dito em relação à ordem, pois elas devem ser muito mais organizadas que eles. Outra discriminação de gênero se opera de maneira bastante visível em relação ao conteúdo esporte, uma vez que as meninas somente irão praticá-lo por volta dos anos de 1960.

Outro aspecto a ser destacado na construção da ordem do discurso presente nos manuais por nós analisados é a mudança do "nós devemos", para "eu devo" e, em seguida, para "eu tenho prazer", isso a partir dos anos de 1950-60. Em outras palavras, passamos de algum modo da moral à ética, do coletivo a uma apropriação do individual e isso não quer dizer liberdade. Nossas análises indicam que, bem ao contrário, isso significa a apropriação individual dos sistemas de controle.

16. Ver por exemplo Tavares (1998). 
Há também uma grande recorrência e constância de temas, assim como uma quantidade de ilustrações que se repetem e que são utilizadas ao longo do tempo. O dogma cristão, ou, mais genericamente, o dogma monoteísta, é o fundamento do sistema moral dito "republicano" na França do período estudado.

\section{CONCLUSÃO}

O discurso dos manuais de higiene e de moral constitui um sistema de controle do verbo sobre a carne com o objetivo de colocar à distância a animalidade e engrandecer o processo de civilização.

Se observarmos o mundo contemporâneo ocidental ou, ao menos, o francês, parece claro que esses discursos absorvidos e internalizados por muitas gerações obtiveram, sem dúvida, certa eficácia. O verbo inscreveu-se na carne para domesticá-la, controlá-la e, em definitivo, inscrever seu poder e seu encarceramento. Os manuais escolares de higiene e de moral na França parecem, pois, constituir o discurso de um biopoder ou de um micropoder no sentido foucaultiano dos termos. ${ }^{17}$

How do we make Angels? Archeology of body in textbooks of moral and hygiene in France (1880-1974)

ABSTRACT: From an archive composed by 342 French textbooks of moral and hygiene, this paper analyzes how a biopower or a micropower is formed in school discourse. Body is here built, flesh is worked as it has been by other Books (biblos in Greek). We can see clearly how the jewish-christian, catholic or, more widely, monotheistic precepts are very present in these textbooks of moral and hygiene published in France between the end of the $19^{\text {th }}$ Century and the 1970's. However, it's important to highlight that these textbooks are part of the Republican school which in France, according to the 1905's laws, is described as separated from the Church and since Jules Ferry (1880- I 882) as a laic institution.

KEY WORDS: Body; moral; hygiene; biopower.

Como se fabrican los ángeles? Una arqueología del cuerpo en los manuales escolares de moral y de higiene en Francia, I880- 1974

RESUMEN: A partir de una colección de 342 manuales escolares franceses de moral e higiene, el artículo analiza como se constituyó un biopoder, o micropoder, en el ámbito del discurso escolar. El cuerpo es allí fabricado y la carne trabajada al igual que por otros tipos de libros

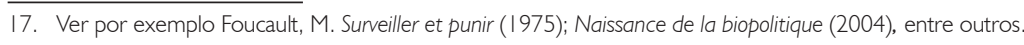


(en griego Biblos). Vemos claramente surgir a través de la arqueología de los manuales escolares de moral e higiene de la Francia de fines del siglo XIX y hasta los años 1970's, que los preceptos judeo-cristianos, católicos, o, mayormente monoteístas, están vivamente presentes. Es importante resaltar que estos manuales son parte constitutiva de la escuela republicana que en Francia es descripta según las leyes de 1905 como institución separada de la iglesia, e incluso después de las leyes elaboradas por Jules Ferry ( 1880-1882), como institución laica. PALABRAS CLAVES: Cuerpo; moral; higiene; biopoder..

\section{FONTES}

ANCEL, L.; BOUCHER, J. Morale: écoles normales. Paris: Delagrave, 1918.

BREMONT, E.; MOUSTIER, D. L'éducation morale et civique à l'école: cours moyen et cours supérieur. Paris: Delalain, 1920.

BOURCEAU, E.; FABRY, R. Lectures expliquées avec enseignement moral et civique: cours moyen. Paris: L'Ecole, 1949.

BOYER, L. Livre de morale des écoles primaires. Paris: Delagrave, 1895.

CAZES, E. Instruction morale et civique: cours moyen. Paris: Delagrave, 1890.

COMPAYRÉ, G. Cours de morale théorique et pratique. Paris: Delaplane, 1895.

DEVINAT, E. Livre de lecture morale: cours moyen. Paris: Larousse, 1890.

DEVINAT, E. Livre de lecture morale: cours moyen et cours supérieur. Paris: Larousse, | 91 I .

DURKHEIM, E. Le suiccide: etude de sociologie. Paris: Payot, 1897.

FAYE, S. Morale: primaire supérieur. Paris: Hachette, 1926.

GUY-GRAND, G. Cours de morale: enseignement primaire supérieur. Paris: Nathan, 1933.

LALOI, P.; PICAVET, F. Instruction morale et civique ou philosophie pratique. Paris: A. Colin, I 888.

PIERRE, A.; MINET, A.; MARTIN MELLE, A. Nos petits amis. Paris: F. Nathan, 1920.

PECAUT, F. Philosophie scientifique et morale: mathématiques et philosophie, candidats à St Cyr. Paris: Garnier, Frères, 1890.

VILLARD, G. Morale en action: six à 10 ans. Paris: Nathan, 1964.

\section{REFERÊNCIAS}

BERNARD, S. Quelle norme dans la représentation des appareils génitaux de l'homme et de la femme dans les manuels scolaires de biologie? In: COLL, C. G. et al. Actes des IIles Journées Pierre Guibbert. Montpellier: IUFM, 2007. 
DE LA FONTAINE, J. Fabulas. São Paulo: Landy, 2004. v. I. p. I65- 166.

DOUGLAS, M. Purity and danger: an analysis of concepts of pollution and taboo. Londres: New Society, 1966.

DURKHEIM, E. Le suicide. Paris: Payot, 1897.

ELIAS, N. La civilisation des mœurs. Paris: Seuil, 1973.

La dynamique de l'occident. Paris: Seuil, 1975.

ELLEINSTEIN, J. (Dir.). Histoire de la France contemporaine. Paris: Ed. Sociales, 1980. 4t.

FOUCAULT, M. Surveiller et punir. Paris: Gallimard, 1975.

Naissance de la biopolitique. Paris: Gallimard, 2004.

Historia da sexualidade l: a vontade de saber. 7. ed. Rio de Janeiro: Graal, 1985.

Em defesa da sociedade: curso no Collège de France (1975-1976). São

Paulo: Martins Fontes, 1999.

GLEYSE, J. La chair et le verbe: un siècle de bréviaires de la république, une archéologie du cors dans les manuels scolaires français de morale et d'hygiène (1880-1974). Paris: L'Harmattan, 2010.

PICARD, D. Du code au désir. Paris: Dunod, 1984.

TAINE, H. Derniers essais de critique et d'histoire. Paris: Hachette, 1894.

TAVARES, O. G. Mens fervida in corpore lacertoso: as atitudes dos atletas olímpicos brasileiros frente ao olimpismo. 1998. Dissertação (Mestrado em Educação Física) - Universidade Gama Filho, Rio de Janeiro, 1998.

THOMAS J. Corps violent, corps soumis: le polissement des mœurs à la fin du moyen-age. Paris: L'Harmattan, 2003.

Recebido em : 3 jun. 2011

Aprovado em : 27 jan. 2012

Endereço para correspondência :

Carmen Lúcia Soares

R-Dr. Sampaio Ferraz, n. I 1 I, apto. 124

| 3024-903 Campinas-SP

Brasil 